
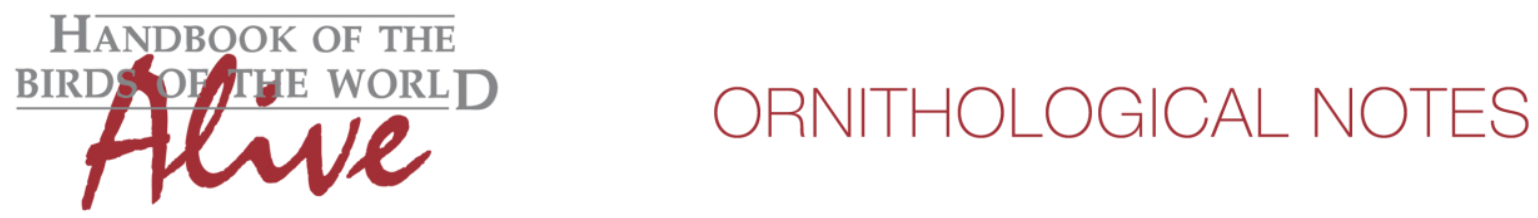

\title{
Notes on the vocalizations of Ethiopian Black-headed Oriole (Oriolus monacha), Mountain Oriole (Oriolus percivali) and Eastern Black- headed Oriole (Oriolus larvatus)
}

Peter Boesman

In the following we briefly analyze and compare voice of Ethiopian Black-headed Oriole (Oriolus monacha), Mountain Oriole (Oriolus percivali) and Eastern Black-headed Oriole (Oriolus larvatus). We also try to quantify the extent of any vocal differences using the criteria proposed by Tobias et al. (2010), as a support for taxonomic review. We have made use of sound recordings available on-line from Xeno Canto (XC).

We will only compare song of the 3 species as most recordings are of this type, but there may be additional vocal differences in the call notes.

Ethiopian Black-headed Oriole (Oriolus monacha) $(n=6)$

Song phrase usually consists of a fast series of melodious, modulated whistles

total length

$\min$. freq.

max. freq.

\# of notes

max. freq. range single note

total freq. range

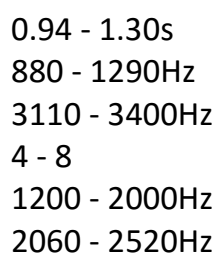

Eastern Black-headed Oriole (Oriolus larvatus) $(n=13)$

Song most often is a melodious whistle going up and down in pitch, usually preceded by 1 or 2 subdued short notes. (Occasionally song is more complex (reportedly at onset of breeding season), this song type is not included in the data below. In this case, closer resemblance with above species)

total length

$\min$. freq.

max. freq.

\# of notes

max. freq. range single note

total freq. range

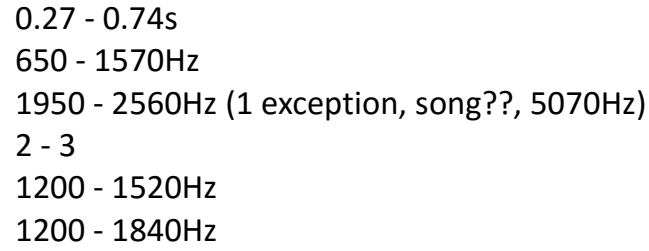

Mountain Oriole (Oriolus percivali) $(n=5)$

Song resembles Eastern Black-headed Oriole, but has more variation and mainly lacks the typical up and down whistle of the latter.

total length

min. freq.

max. freq.

\# of notes

max. freq. range single note

total freq. range

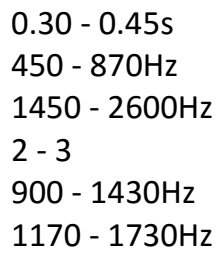



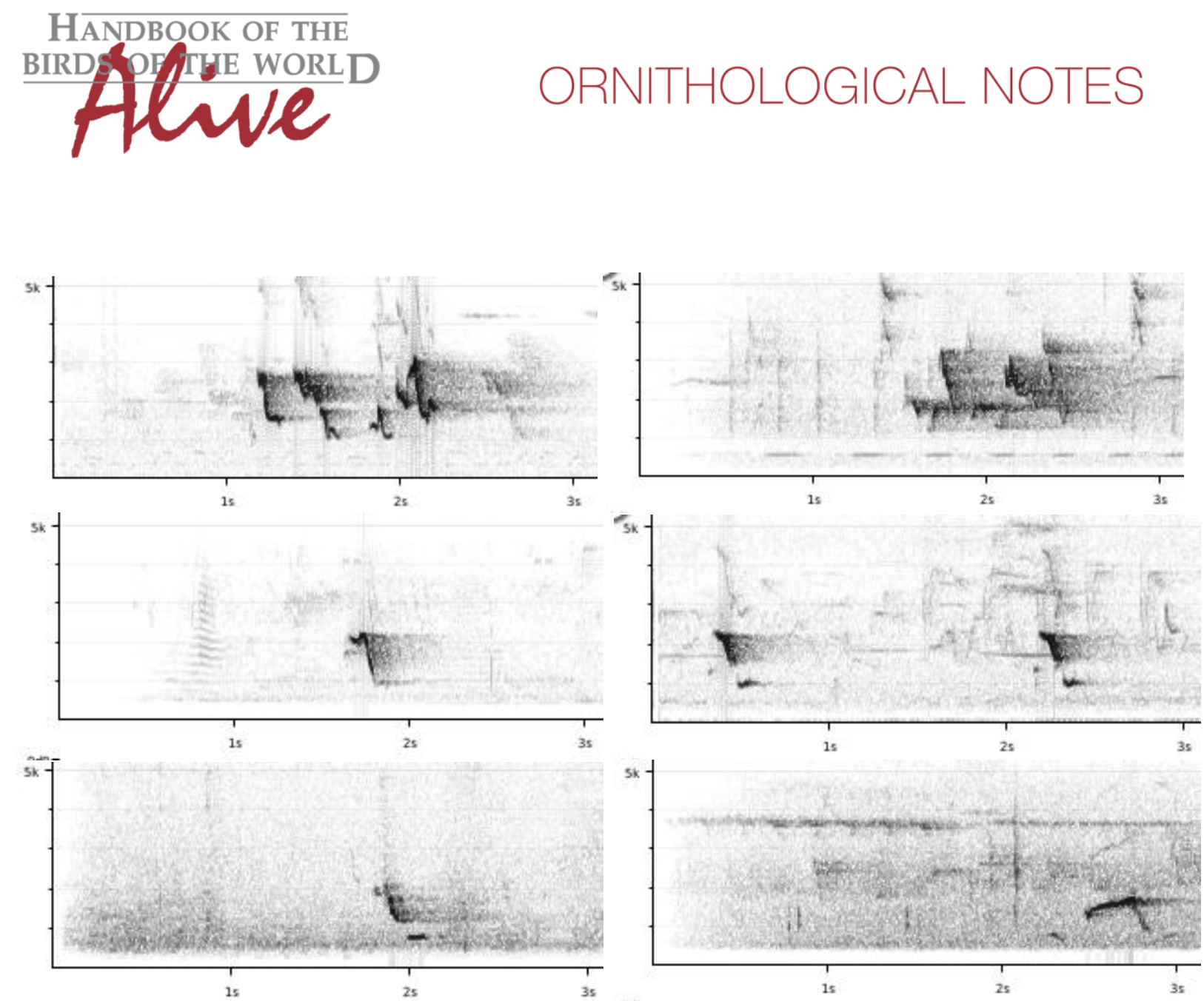

Figure 1: most commonly heard song of $O$. monacha (top), $O$. larvatus (middle) and $O$. percivali (bottom)

From the above, differences are quite clear:

Ethiopian Black-headed Oriole typically has a longer song phrase (score 2), with more notes which are modulated and sound less flute-like (score 2). Song reaches higher frequencies and a higher frequency range (score 2 ). If we apply Tobias criteria, this leads to a total vocal score of 4 in comparison with the two other species.

Mountain Oriole differs slightly from Eastern Black-headed Oriole, in having a more varied song, with whistles often downslurred or flat, rarely uttering whistles going up and down in pitch as in Eastern Black-headed Oriole. Basic sound parameters do mainly overlap however, and song probably not always safely told apart. Total vocal score 1 .

We could also compare with the 2 races of Western Black-headed Oriole:

brachyrhynchus $(\mathrm{n}=9)$

total length

min. freq.

max. freq.

\# notes

longest note

highest freq. range single note

freq. range
$0.42-0.90 \mathrm{~s}$

$650-780 \mathrm{~Hz}(\mathrm{Av} 688 \mathrm{~Hz}, \mathrm{SD} 48 \mathrm{~Hz})$

$1290-1880 \mathrm{~Hz}($ Av $1560 \mathrm{~Hz}$, SD $191 \mathrm{~Hz})$

3 - 5 (mainly 3 )

$0.15-0.31 \mathrm{~s}$

$300-900 \mathrm{~Hz}$

$640-1100 \mathrm{~Hz}$ 


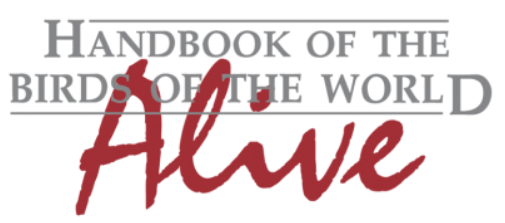

laetior $(\mathrm{n}=6)$

total length

min. freq.

max. freq.

\# notes

longest note

highest freq. range single note

freq. range

\section{ORNITHOLOGICAL NOTES}

$0.32-0.69 \mathrm{~s}$

$750-1000 \mathrm{~Hz}(\mathrm{Av} 850 \mathrm{~Hz}, \mathrm{SD} 91 \mathrm{~Hz})$

$1400-2700 \mathrm{~Hz}$ (Av $1878 \mathrm{~Hz}$, SD $398 \mathrm{~Hz}$ )

$2-4$

$0.12-0.35 s$

$400-780 \mathrm{~Hz}$

$400-1900 \mathrm{~Hz}$

Without going into more detail, it is clear that vocal differences of all races in this complex except monacha are rather subtle.

This note was finalized on 13th October 2015, using sound recordings available on-line at that moment. We would like to thank in particular the many sound recordists who placed their recordings for this species on XC.

\section{References}

Tobias, J.A., Seddon, N., Spottiswoode, C.N., Pilgrim, J.D., Fishpool, L.D.C. \& Collar, N.J. (2010). Quantitative criteria for species delimitation. Ibis 152(4): 724-746.

\section{Recommended citation}

Boesman, P. (2016). Notes on the vocalizations of Ethiopian Black-headed Oriole (Oriolus monacha), Mountain Oriole (Oriolus percivali) and Eastern Black-headed Oriole (Oriolus larvatus). HBW Alive Ornithological Note 161. In: Handbook of the Birds of the World Alive. Lynx Edicions, Barcelona. (retrieved from http://www.hbw.com/node/932091 on 18 August 2016). 